\title{
New generation of electrochemical immunoassay based on polymeric nanoparticles for early detection of breast cancer
}

This article was published in the following Dove Press journal:

International Journal of Nanomedicine

13 April 2017

Number of times this article has been viewed

\author{
Fouzi Mouffouk' \\ Sihem Aouabdi² \\ Entesar Al-Hetlani' \\ Hacene Serrai ${ }^{3}$ \\ Tareq Alrefae ${ }^{4}$ \\ Liaohai Leo Chen ${ }^{5}$ \\ 'Department of Chemistry, Kuwait \\ University, Safat, Kuwait; ${ }^{2}$ King \\ Abdullah International Medical \\ Research Center (KAIMRC), \\ Jeddah, Kingdom of Saudi Arabia; \\ ${ }^{3}$ Department of Radiology and \\ Nuclear Medicine, University Hospital \\ of Gent (UZG), Gent, Belgium; \\ ${ }^{4}$ Department of Physics, Kuwait \\ University, Safat, Kuwait; ${ }^{5}$ Surgical \\ Precision Research Lab. Department \\ of Surgery, University of Illinois at \\ Chicago, IL, USA
}

\begin{abstract}
Screening and early diagnosis are the key factors for the reduction of mortality rate and treatment cost of cancer. Therefore, sensitive and selective methods that can reveal the low abundance of cancer biomarkers in a biological sample are always desired. Here, we report the development of a novel electrochemical biosensor for early detection of breast cancer by using bioconjugated self-assembled $\mathrm{pH}$-responsive polymeric micelles. The micelles were loaded with ferrocene molecules as "tracers" to specifically target cell surface-associated epithelial mucin (MUC1), a biomarker for breast and other solid carcinoma. The synthesis of target-specific, ferrocene-loaded polymeric micelles was confirmed, and the resulting sensor was capable of detecting the presence of MUC1 in a sample containing about 10 cells $/ \mathrm{mL}$. Such a high sensitivity was achieved by maximizing the loading capacity of ferrocene inside the polymeric micelles. Every single event of binding between the antibody and antigen was represented by the signal of hundreds of thousands of ferrocene molecules that were released from the polymeric micelles. This resulted in a significant increase in the intensity of the ferrocene signal detected by cyclic voltammetry.
\end{abstract}

Keywords: electrochemical immunoassay, polymeric nanoparticles, breast cancer biomarkers, biosensors

\section{Introduction}

Breast cancer is still one of the principal causes of cancer mortality in women. However, there has been a continued decline in death rates over the last decades due to the incremental advances in the medical field, despite an increasing incidence of breast cancer. Therefore, preventive screening and early diagnosis are vital components of a comprehensive cancer control program. Immunoassays are widely used as analytical tools in clinical and pharmaceutical fields to detect and quantify biomolecules in mixtures such as serum or urine through the use of an immunoglobulin. ${ }^{1,2}$ Such tests employ an array of different signaling molecules to allow the detection of the antibody-antigen interaction. These signaling molecules are usually chemically conjugated to the desired antibody or antigen. Currently, enzymatic signaling molecules are most widely used in immunoassays (eg, enzyme-linked immunosorbent assay, ELISA). ${ }^{3}$ These enzymes enable detection due to change in color in the presence of certain enzymatic substrates. Alternatively, detection can be achieved through the enhancement of the generated chemiluminescence signal; it was reported that up to 1000-fold signal improvement can be achieved in the presence of certain molecules such as horseradish peroxidase. ${ }^{4,5}$ Other signaling mechanisms reported include the
Correspondence: Fouzi Mouffouk Department of Chemistry, Kuwait University, PO Box 5969, Safat

13060, Kuwait

Tel +965 988I 9600

Email fmouffouk@ku.edu.kw 
use of fluorescence dye molecules, ${ }^{6}$ radioactive isotopes, ${ }^{7}$ DNA reporters, ${ }^{8,9}$ and fluorogenic reporters. ${ }^{10,11}$

Electrochemical detection is considered as one of the most reliable and efficient techniques to detect biomolecules within biological samples. ${ }^{12}$ However, the implementation of this method in the field of immunoassay remains very limited compared to optical detection systems. Although several attempts were made in the past by scientists to develop immunosensors using enzymes that convert an enzyme substrate into an electrochemically measurable product, efforts so far have yielded no method that can rival the existing systems. This limitation was mostly attributed to the difficulty in achieving an acceptable level of signalto-noise ratio due to the following reasons: 1) nonspecific adsorptions of the enzymes occur within the detection vicinity; and 2) most of the antibody-binding capability is often lost during the immobilization step because of the nonspecific antibody adsorption on the electrode surface. Therefore, these limitations usually dramatically affect the reliability of the immunoassay. Gehring et a ${ }^{13}$ developed an amperometric assay for the detection of Salmonella typhimurium cells which were apprehended using conjugated magnetic beads. The beads were then coated on graphite electrodes, and the alkaline phosphatase (AP)-labeled goat anti-Salmonella antibody catalyzed the production of an electroactive para-aminophenol from its substrate, paraaminophenyl phosphate, which was monitored electrochemically. The obtained signal was directly related to the number of bacterial cells, and the sensor had a sensitivity of $8 \times 10^{3}$ cells $/ \mathrm{mL}$.

Thus, to overcome such inconveniences, liposomes encapsulated with marker molecules or enzymes have been used. ${ }^{14}$ However, the main downside of liposomes is their instability throughout their use or storage, ${ }^{15}$ which is mainly related to their surface properties. Several solutions were investigated to improve liposome stability. For example, the modification of the composition of the liposome lipids via the incorporation of a bio-adhesive molecule such as chitosan or cholesterol in their membrane significantly improved their stability, ${ }^{16}$ and also, the cross linking of the hydrophobic core of the liposome membrane via polymerization, ${ }^{17}$ or through surface-active polymer additives, ${ }^{18}$ has shown positive effect on their stability. So far, such improvements have been revealed to be very costly and increase the complexity of the fabrication process of these liposome immunoassays which cause them to be less efficient even with enhanced sensitivity range. Another major concern with using con- ventional liposomes in immunoassay is leakage, especially in the case of low-abundance protein detection. It was found that when small molecules are encapsulated inside liposome as "tracers", these molecules have the tendency to leak into the outside medium. Such a problem can greatly affect the performance of the immunoassay. ${ }^{19,20}$

Therefore, developing a method that does not involve antibody immobilization on an electrode surface or rely on enzymatic reactions to generate the electrochemical signal is highly in demand. Such methods should provide a more robust and stable carrier which will present an important leap toward a more efficient and reliable biosensor for medical and food safety applications. Electrochemical immunoassays based on loaded $\mathrm{pH}$-sensitive polymeric micelles offer an attractive alternative over the existing procedures, especially in applications where high selectivity, sensitivity, and stability are needed.

In this work, the MUC1 glycoprotein (protein at the cell surface) was selected as a target for our new biosensor because it is frequently overexpressed in human cancers, particularly in breast cancer. ${ }^{21}$ In addition, MUC1 has shown a great potential for early detection and grading of tumors, along with the tumor responses to therapy. Furthermore, cell surface-associated epithelial mucin (MUC1) has been tested as a target for gold nanoparticle-mediated cancer diagnosis and therapy. ${ }^{22-24}$

MUC1 is a high-molecular-weight plasma membranebound protein with an obtruding O-glycosylated N-terminal domain that overhangs from the apical surface of glandular epithelial cells in the breast, colon, and lung. ${ }^{25}$ MUC1 has 72-aa C-terminal domain and a single transmembrane domain and is regulated and cleaved by tyrosine phosphorylation. ${ }^{26}$

In this paper, we report the development of an exceedingly sensitive and fast bioassay to probe and quantify biomarkers (breast cancer biomarker). Since these polymeric nanoparticles have been shown to be efficient and stable carriers for hydrophobic molecules, we encapsulated tracer signal generator molecules (ferrocene) inside these polymeric nanoparticles, and upon their release, the ferrocene molecules acted as signal amplifiers for the binding between the antibody and antigen.

\section{Experimental section} Reagents and materials

Ethanol $(96 \%, v / v)$ from AGA, HPLC-grade tetrahydrofuran (THF) from Sigma-Aldrich, hydrochloric acid (37\%, 
w/w), MTT, Trizol reagent paraformaldehyde, and methoxypolyethylene glycol N-hydroxysuccinimide ester from Sigma-Aldrich were used. Monoclonal antibodies against the human MUC1 protein, SM3 (Abcam), and C595 (Santa Cruz Biotechnology) were obtained. For cell culture, complete Dulbecco's Modified Eagle's Medium or RPMI1640 culture media (DMEM or RPMI1640 basic medium supplemented with 10\% fetal bovine serum [FBS; PAA], 2 mM glutamine, 100 units/mL penicillin, and $100 \mu \mathrm{g} / \mathrm{mL}$ streptomycin) was prepared. Cell lines were acquired commercially; MCF-7 from ATCC (ATCC HTB-22) and MDA-MB-468 from ATCC (ATCC HTB-132).

\section{Equipment}

For ${ }^{1} \mathrm{H}$ nuclear magnetic resonance (NMR) experiments, Bruker ARX 400 was used, while spectrofluorometer (Jobin Yvon - HORIBA Scientific) was used for measuring fluorescence spectra. All emission spectra were obtained using 1 -cm quartz cuvettes at $\lambda=334 \mathrm{~nm}$ (Hellma Quartz-Suprasil). White-light and fluorescence images of living cells were obtained via Leica DM IL inverted fluorescence microscope coupled to a digital CCD camera. Light scattering experiments were performed using Brookhaven Instruments BI-200SM multi-angle particle size analyzer utilizing dynamic light scattering (DLS) and static light scattering (SLS) modes.

\section{Synthesis of the poly(ethylene glycol- b-trimethylsilyl methacrylate) (PEG-b- PTMSMA)}

In nitrogen-charged Schlenk tube, $0.8 \mathrm{~g}$ of macro-CTA was dissolved in $10 \mathrm{~mL}$ THF. Then, $0.030 \mathrm{~g}$ of azobisisobutyronitrile $(\mathrm{AIBN})$ and $3.5 \mathrm{~mL}$ of trimethylsilyl methacrylate (TMSMA) were added. After that, the mixture was placed in an oil bath under stirring at $60^{\circ} \mathrm{C}$ for $24 \mathrm{~h}$. The mixture was then cooled down, and $10 \mathrm{~mL}$ of THF was added to dilute the mixture. After solvent evaporation, the obtained crude was dissolved in methanol, and the polymer was recovered via precipitation upon the addition of water. A white solid was obtained and dried under vacuum at $60^{\circ} \mathrm{C}$ overnight, yielding $2 \mathrm{~g}(55 \%)$ of the polymer. ${ }^{1} \mathrm{H}$ NMR (dimethylsulfoxide, DMSO) $\delta 0.055\left(\mathrm{~s},\left(\mathbf{C H}_{3}\right)_{3} \mathrm{Si}\right), 1.096\left(\mathrm{~s}, \mathbf{C H}_{3} \mathrm{C}-\mathrm{C}=\mathrm{O}\right), 1.277$ (s, $\left.\mathbf{C H}_{3} \mathrm{C}-\mathrm{C}=\mathrm{O}\right), 1.778$ (s, $\left.\mathbf{C H}_{2} \mathrm{C}-\mathrm{C}=\mathrm{O}\right), 1.890$ (s, $\mathbf{C H}_{2} \mathrm{C}-$ $\mathrm{C}=\mathrm{O}), 3.256\left(\mathrm{~s}, \mathbf{C H}_{3} \mathrm{O}-\left(\mathrm{CH}_{2} \mathrm{CH}_{2} \mathrm{O}\right)_{n}\right), 3.54\left(\mathrm{~s},\left(\mathbf{C H}_{2} \mathbf{C H}_{2} \mathrm{O}\right)_{n}\right)$, and 4.560 (q, $\left.\mathrm{CH}_{3} \mathbf{C H}_{2} \mathrm{O}-\mathrm{C}=\mathrm{S}\right)$. DP ${ }_{n}(\mathrm{NMR})=45$. Gel permeation chromatography (GPC) analysis exposed only one modal molecular weight distribution, from which a value of $M_{\mathrm{n}}=9 \mathrm{kDa}^{27}$ was deducted.

\section{Preparation of loaded polymeric nanoparticles}

Loaded polymeric nanoparticles were prepared as follows: $30 \mathrm{mg}$ of PEG-b-PTMSMA and $0.5 \mathrm{mg}$ of either 1-methylpyrene (as fluorophore) or ferrocene (as electrochemical active complex) were dissolved in $0.3 \mathrm{~mL}$ of DMF. The mixture was stirred for a period of $3 \mathrm{~h}$ at room temperature. Next, $1.0 \mathrm{~mL}$ of Milli-Q water was added to the solution at a rate of one drop every $10 \mathrm{~s}$ to induce the micellization. The resulting mixture was then dialyzed against Milli-Q water for 3 days at $25^{\circ} \mathrm{C}$ (water was replaced twice a day). A dialysis cassette with $10 \mathrm{kDa}$ cut-off capability was used to remove any un-encapsulated molecules and non-self-assembled polymer molecules from the mixture.

\section{Preparation of bioconjugated magnetic beads with anti-MUCI (SM3)}

One hundred micrograms of anti-MUC1 antibodies was added to $500 \mu \mathrm{L}$ tosylactivated magnetic beads $\left(9 \times 10^{8}\right.$ beads $)$ in $0.1 \mathrm{M}$ borate buffer ( $\mathrm{pH}$ 9.5). The mixture was mixed for $12 \mathrm{~h}$ under slow tilt rotation at $40^{\circ} \mathrm{C}$. Unreacted anti-MUC1 antibodies were then washed off using magnetic separation. Subsequently, the magnetic beads were washed with phosphate-buffered saline (PBS) ( $\mathrm{pH} 7.4$ ) containing $0.1 \%$ $(\mathrm{w} / \mathrm{v})$ bovine serum albumin $(\mathrm{BSA})$ for $20 \mathrm{~min}$ at $40^{\circ} \mathrm{C}$, followed by deactivating the remaining tosylactivated magnetic beads with $0.4 \mathrm{M}$ Tris buffer $(\mathrm{pH} 8.5)$ containing $0.1 \%(\mathrm{w} / \mathrm{v})$ BSA. The obtained bioconjugated magnetic beads were washed with PBS buffer (pH 7.4).

\section{Bioconjugation of polyethylene glycol with MUCI antibodies}

Bioconjugation of polyethylene glycol with C595 mAb was achieved by adding $4 \mathrm{mg}$ of methoxypolyethylene glycol $\mathrm{N}$-hydroxysuccinimide ester to a solution containing $3 \mu \mathrm{g}$ of $\mathrm{C} 595 \mathrm{mAb}$ in $500 \mu \mathrm{L}$ of $0.1 \mathrm{M}$ bicarbonate buffer ( $\mathrm{pH} 8.3$ ). The mixture was softly stirred for 3 days under slow tilt rotation at $4^{\circ} \mathrm{C} .^{28,29}$

\section{Preparation of loaded bioconjugated micelles with C595 antibody}

Twenty milligrams of PEG-b-PTMSMA block copolymer and $0.5 \mathrm{mg}$ of ferrocene were dissolved in $0.5 \mathrm{~mL}$ of the freshly prepared biotin-PEO (MUC1 antibodies-PEO). The solution was agitated for $3 \mathrm{~h}$ at $25^{\circ} \mathrm{C}$. Then, $2 \mathrm{~mL}$ of water was added to the mixture at a rate of $10 \mu \mathrm{L}$ every $10 \mathrm{~s}$ to 
stimulate the micellization. The resulting mixture was then placed in a dialysis cassette of $10 \mathrm{kDa}$ molecular weight cutoff and dialyzed against Milli-Q water for 3 days at $25^{\circ} \mathrm{C}$ (water was replaced twice a day). After that, the solution was diluted five times with PBS buffer. The presence of the antibody on the micelles (polymeric nanoparticles) was tested using ELISA (data not shown).

\section{Cell lines}

The MCF-7 (human breast adenocarcinoma) and S17 (mouse bone marrow stroma) cell lines and MDA-MB-468 cell line (human breast adenocarcinoma) were kept in DMEM culture medium. Cells were cultured at $37^{\circ} \mathrm{C}$ under humidified atmosphere of $5 \% \mathrm{CO}_{2}$.

\section{Cell culture}

The MCF-7 and MDA-MB-468 and S17 adherent cell lines were kept in DMEM culture medium complemented with $10 \%$ FBS, $200 \mathrm{mM}$ glutamine, 10,000 units/mL penicillin, and $10,000 \mu \mathrm{g} / \mathrm{mL}$ streptomycin. All cell culture incubations were performed at $37^{\circ} \mathrm{C}$ under humidified atmosphere of $5 \%$ $\mathrm{CO}_{2}$. Cells were thawed at $37^{\circ} \mathrm{C}$ and pipetted into $10 \mathrm{~mL}$ of prewarmed medium. Next, the cells were centrifuged at $300 \mathrm{rpm}$ for $5 \mathrm{~min}$ to eliminate DMSO. Then, the supernatant was discarded, and the pellets of cells were resuspended in $2 \mathrm{~mL}$ of fresh medium. The cells were seeded into T25 flasks, and $8 \mathrm{~mL}$ of the medium was added for a final volume of $10 \mathrm{~mL}$. The medium was changed every 2 days. For cell count, medium was first removed from the flask, cells were washed with warm PBS, and then $1 \mathrm{~mL}$ of $0.25 \%$ trypsin was added per $59 \mathrm{~cm}^{2}$ to detach the cells. Cells were allowed to detach for $1-5 \mathrm{~min}$ (depending on the cell line) at $37^{\circ} \mathrm{C}$. DMEM was added to the flask to deactivate the trypsin, before transferring the cells to a $15 \mathrm{~mL}$ centrifuge tube. Cells were centrifuged at $300 \mathrm{rpm}$ for $5 \mathrm{~min}$, and the pellet was resuspended in $1 \mathrm{~mL}$ medium for cell count. The cell pellet was dissociated by pipetting gently up and down to get a single cell suspension.

Thirty microliters of $0.4 \%$ trypan blue was added to $30 \mu \mathrm{L}$ of cell suspension. Then, $10 \mu \mathrm{L}$ of the cells with trypan blue was loaded on each side of a hemocytometer. Viable cells that did not take up the trypan blue were counted on an inverted light microscope. The cells were counted in four $1 \mathrm{~mm}^{2}$ squares. The equation to calculate the cell number per cubic millimeter is:

Cell number $/ \mathrm{mm}^{3}=$ Number of cells counted per square millimeter $\times$ Dilution used $\times 10$

\section{Testing the selectivity of the polymeric micelle toward cancer cells}

Seeded MCF-7 cells in culture plates were allowed to attach for $24 \mathrm{~h}$ at $37^{\circ} \mathrm{C}$. Polymeric nanoparticles bioconjugated with C595 or SM3 antibody and loaded with fluorescence dye (1-methylpyrene) were added to the cell culture and allowed to incubate for $1 \mathrm{~h}$ at $37^{\circ} \mathrm{C}$. As a control, we used unlabeled 1-methylpyrene-loaded polymeric nanoparticles. Surplus of the polymeric nanoparticles was eliminated via washing three times with PBS buffer. Both the cell lines (S17 and MCF-7) were grown together on glass cover slips (at a ratio of 5 to 1 ). The cells were then allowed to attach for a period of $24 \mathrm{~h}$ at $37^{\circ} \mathrm{C}$. The 1 -methylpyrene-loaded and bioconjugated polymeric nanoparticles with MUC1 were added to the cells and incubated for $1 \mathrm{~h}$ at $37^{\circ} \mathrm{C}$. Then, the cells were washed three times with PBS buffer and fixed with 4\% paraformaldehyde for $40 \mathrm{~min}$. Next, the cover slip was mounted and observed under a fluorescence microscope.

\section{Preparation of MUCI biomarker}

The S17 (mouse bone marrow stroma) and MCF-7 (human breast adenocarcinoma) cells in DMEM culture medium were separately detached into single cells by incubating with trypsin-ethylene diamine tetraacetic acid for $10 \mathrm{~min}$ at $37^{\circ} \mathrm{C}$. The cells were shaken off, washed three times with PBS buffer, and centrifuged at 3,000 rpm for $4 \mathrm{~min}$. S17 and MCF-7 cells were then resuspended in $2 \mathrm{~mL}$ of membrane buffer comprising protease inhibitors and then lysed by means of nitrogen disruptor at 500 psi for $15 \mathrm{~min}$. The purified supernatants were used for bioassay.

\section{Detection of breast cancer biomarker}

Different concentrations of cells for MCF-7 and S17 cell lysis were prepared $(1,000,100$, and 10 cells $/ \mathrm{mL})$ and separately incubated along with $20 \mu \mathrm{L}$ of SM3-coated magnetic beads for a period of $1 \mathrm{~h}$ under slow tilt rotation at $4^{\circ} \mathrm{C}$. After incubation, the unbound MUC1 was removed by washing the beads four times with PBS buffer using magnetic separation.

Next, $200 \mu \mathrm{L}$ of the polymeric nanoparticles conjugated with anti-MUC1 was added to the bioconjugated magnetic beads. The mixture sandwich magnetic beads (beads-SM3MUC1) and bioconjugated polymeric micelles were stirred for $1 \mathrm{~h}$ by slow tilt rotation at $4^{\circ} \mathrm{C}$. The unbound bioconjugated polymeric nanoparticles were washed off using magnetic separation. After washing the beads four times with PBS buffer, the ferrocene molecules were released from the polymeric micelles by decreasing the $\mathrm{pH}$ to 5 . The redox signal of the released ferrocene molecules inside 
the electrochemical cell was measured and recorded using Autolab potentiostat (Metrohm Autolab).

\section{Electrochemistry experiments}

Electrochemistry experiments were performed using cyclic voltammetry (CV) in a one-compartment cell with three-electrode formation using potentiostat with GPE and FRA software programs (Autolab PG-30). The working electrode (WE) used in this experiment was platinum disc electrode (10 $\mu \mathrm{m}$ diameter) and the counter electrode employed was platinum gauze, while the reference electrode (RE) was made from saturated calomel. The three electrodes were regularly rinsed with distilled water and allowed to dry under argon before inserting them in the electrochemical cell. The built-in Luggin capillary allowed the positioning of the RE as close as possible to the WE with the intention of reducing the uncompensated solution resistance. The cathodic $\left(E_{\mathrm{pc}}\right)$ and anodic $\left(E_{\mathrm{pa}}\right)$ peaks of ferrocene $\left(\mathrm{Fe}\left(\mathrm{C}_{2} \mathrm{H}_{5}\right)_{2}{ }^{+} \mathrm{Fe}\left(\mathrm{C}_{5} \mathrm{H}_{5}\right)\right)$ were achieved at a scan rate of $0.10 \mathrm{~V} / \mathrm{s}$.

\section{Results and discussion Preparation of polymeric micelles}

$\mathrm{pH}$-sensitive polymeric nanoparticles have gained a great deal of attention in the fields of drug delivery and medical imaging in part due to their great stability and their high encapsulation capacity within their core, of a wide variety of molecules, during self-assembly into micelles (Scheme 1). ${ }^{30,31}$

Such polymers bear silicon moieties as acid-labile groups that can be cleaved under mild acidic conditions of $\mathrm{pH}(5-6)$, rendering the polymer hydrophilic. This causes the polymeric particles to disintegrate and eventually release their contents. PEG-b-PTMSMA was produced using reversible addition-fragmentation chain transfer from TMSMA using (O-ethylxanthate)-methylPEG as a macro-chain transfer agent and AIBN as a radical initiator.

The polymer was characterized by ${ }^{1} \mathrm{H}$ NMR spectroscopy and triple-detection GPC. A DP ${ }_{n}$ of 45 was deduced from the NMR peak area at $3.54 \mathrm{ppm}\left(\mathrm{CH}_{2}\right.$ in PEG) and that at $1.09 \mathrm{ppm}\left(\mathrm{CH}_{3}\right.$ in TMSMA). GPC analysis disclosed only one-mode molecular weight distribution, from which the value of $M_{\mathrm{n}}=9 \mathrm{kDa}$ was calculated. Both the NMR and Fourier transform infrared spectra indicated the presence of TMSMA units via the singlet at $0.056 \mathrm{ppm}$ corresponding to $\left(\mathrm{CH}_{3}\right)_{3} \mathrm{Si}$ and the bands at $1,259,1,178$, and $840 \mathrm{~cm}^{-1}$ that were consistent with the group $\mathrm{Si}\left(\mathrm{CH}_{3}\right)_{3}$. On the matrix-assisted laser desorption/ionization time of flight spectrum, the interpeak distances matching the masses of both repeating units were 158 for TMSMA and 44 for ethylene glycol.

The preparation of native and dye-encapsulated PEG-bPTMSMA nanoparticles was carried out using a modified procedure as mentioned in the "Experimental section", and both native and loaded polymeric micelles were characterized via transmission electron microscopy and DLS. Based on DLS measurements, the native polymeric nanoparticles were found to have an average diameter of $24 \mathrm{~nm}$ as demonstrated in Figure 1, while the electroactive complex (ferrocene)-encapsulated polymeric nanoparticles exhibited a significant increase in diameter with an average value of $40 \mathrm{~nm}$ as revealed in Figure 2.

The increase in micelles size can be attributed to the amount of ferrocene encapsulated within them. The ferrocene concentration inside the micelles was determined based on the average molecular mass difference $\left(\Delta m=4.8 \times 10^{-17} \mathrm{~g}\right)$ between the micelle loaded with the ferrocene $\left(\mathrm{m}_{2}\right)$ and the
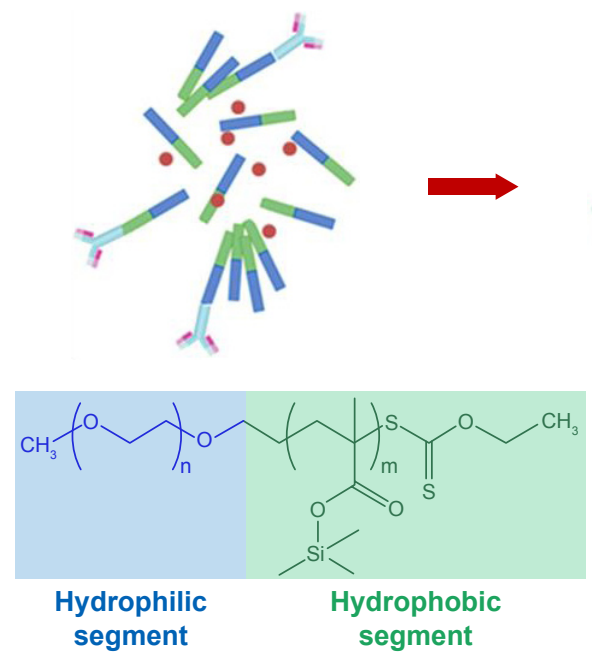
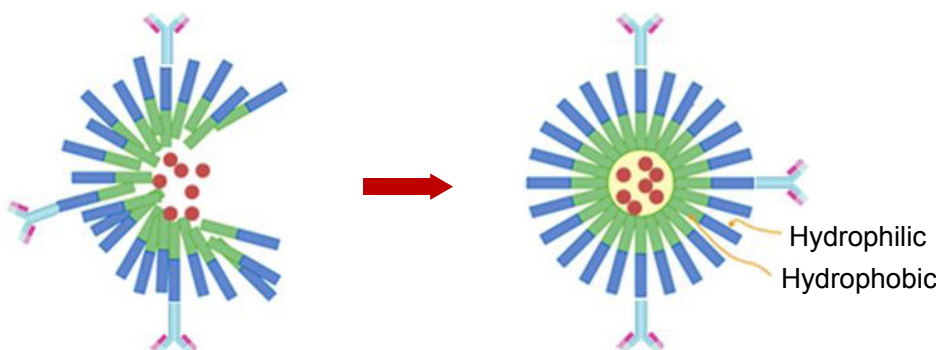

Scheme I Poly(ethylene glycol-b-trimethylsilyl methacrylate) structure and the representation of self-assembly process of the polymer into micelles (polymeric nanoparticles). 

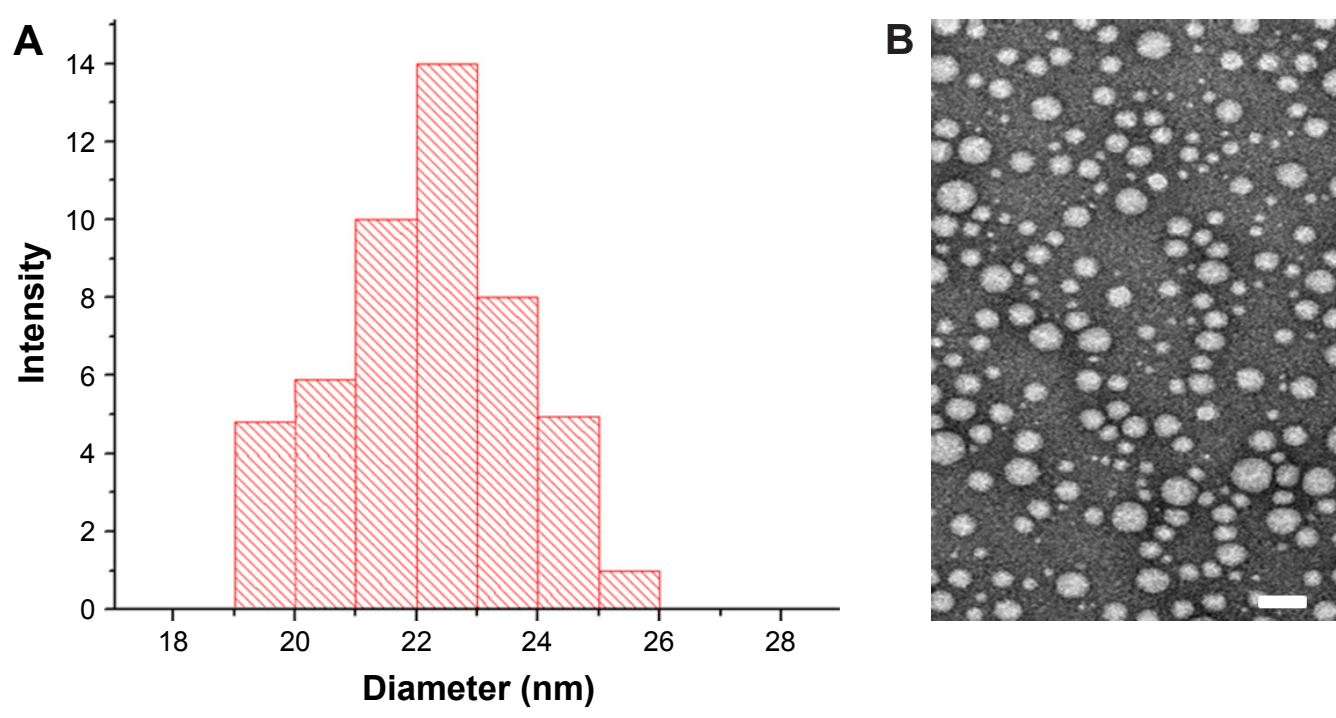

Figure I (A) Dynamic light scattering of unloaded polymeric nanoparticles. (B) Transmission electron microscopy of unloaded polymeric nanoparticles (bar scale, 50 nm).

micelle without the ferrocene, that is, native micelle $\left(\mathrm{m}_{1}\right)$ that was derived from SLS, and the molecular weight of one dye molecule which was $4.4 \times 10^{-22} \mathrm{~g}$. Thus, we estimated the number of dye molecules that can be encapsulated inside one micelle with an Rh of $37 \mathrm{~nm}$ to be $\sim 110,000$. As a result, the release of such a concentration of the ferrocene molecules into the solution provided important signal amplification for probing the antigen-antibody binding event.

Ferrocene encapsulation and leakage investigations were established by the toxicity study of the ferrocene-encapsulated nanoparticles, which were incubated with mouse embryonic stem cells (due to their sensitivity). When free ferrocene $(40 \mu \mathrm{M})$ was in direct contact with the cells, the cell death was observed in 3 days. However, upon mixing the same type of cells with ferrocene $(400 \mu \mathrm{M})$ encapsulated within polymeric micelles, the cell colony growth stayed normal for 3 days (data not shown). The results suggested that the ferrocene molecules were encapsulated and kept inside the micelles and were completely isolated from the cells.

\section{Assessment of polymeric nanoparticles' targeting of cancer cells}

To evaluate the ability of anti-MUC1-bioconjugated micelles to target cancer cells and confirm its selectivity toward MUC1-expressing cells, we loaded the polymeric nanoparticles with 1-methylpyrene (fluorescent dye). To target MUC1-expressing cells, fluorophore-loaded micelles were bioconjugated with the anti-MUC1. We used the MCF-7 cell line, which displayed the highest levels of MUC1 expression, and the mouse bone marrow stroma S17 cell line as a negative control (Figure 3).

Anti-MUC1-bioconjugated and non-conjugated fluorophore-loaded micelles were incubated for different periods of time with each cell line, and the incorporation
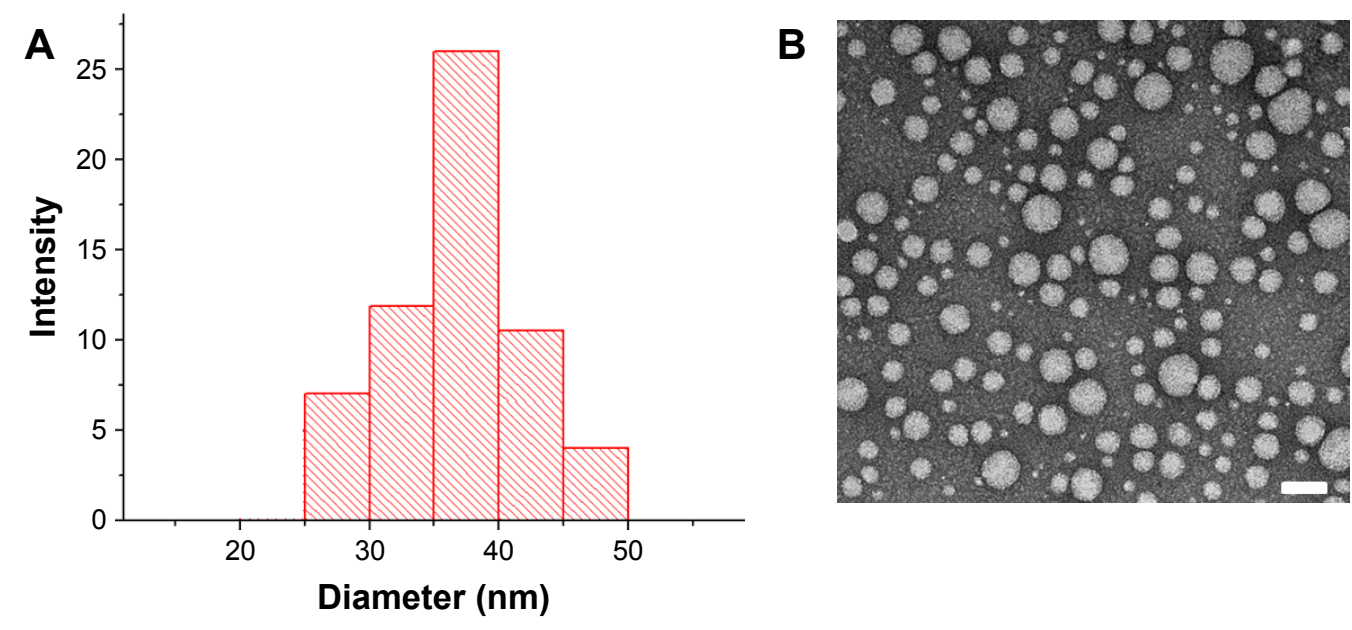

Figure 2 (A) Dynamic light scattering and (B) transmission electron microscopy of ferrocene-loaded polymeric nanoparticles (bar scale, $50 \mathrm{~nm}$ ). 


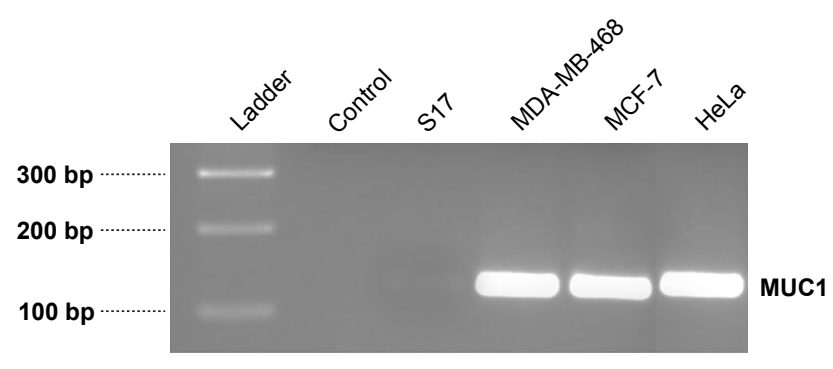

Figure 3 Surveying mRNA level of MUCI in SI7, MDA-MB-468, MCF-7 and HeLa cell line by RT-PCR.

of 1-methylpyrene was assessed using a fluorescence microscope. Thus, MCF-7 cell incubation with anti-MUC1bioconjugated micelles resulted in a higher percentage of fluorescent cells than incubation with non-conjugated micelles (Figure 4).

In contrast, incubation of S17 cells with anti-MUC1bioconjugated micelles did not result in a higher proportion of fluorescent S17 cells, as compared to non-conjugated micelles (Figure 5). Jointly, these results revealed the selectivity of these bioconjugated nanoparticles toward MUC1-expressing cells and also established the fact that these micelles released their contents within cells.

The goal of the next experiment was to examine if antihuman MUC1 polymeric nanoparticles were able to specifically attach to MDA-MB-468 cells, even when these cells were mixed in inferior number with $\mathrm{S} 17$ mouse cells. Thus, S17 and MDA-MB-468 cells were cultured in a 5:1 ratio. Then, the mixed culture was incubated with anti-MUC1 polymeric micelles for a period of $1 \mathrm{~h}$. After that, the mixed culture was washed several times with PBS buffer before observation under the fluorescence microscope.

We witnessed that the MDA-MB-468 cells, which displayed round morphology (Figure 6B), incorporated far more fluorescence dye (1-methylpyrene) compared to S17 cells, which displayed elongated morphology (Figure 6C) with almost no fluorescence (Figure 6A). This clearly demonstrates the high selectivity of these bioconjugated particles toward MUC1-expressing cells.
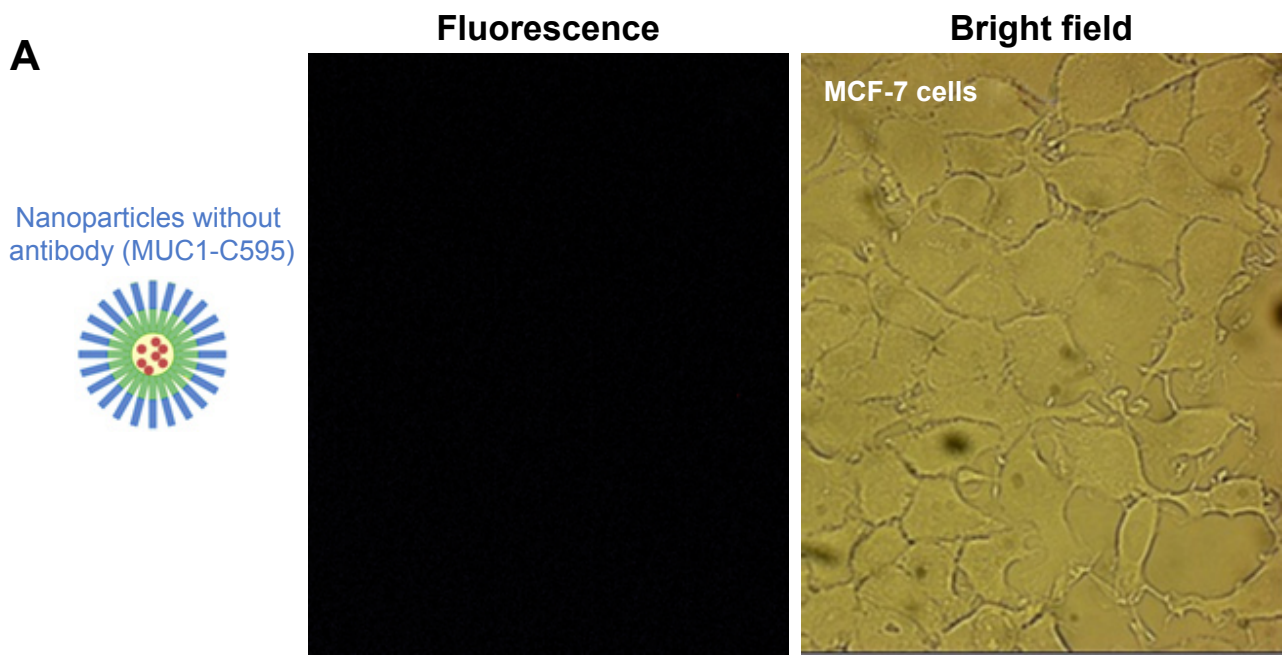

B
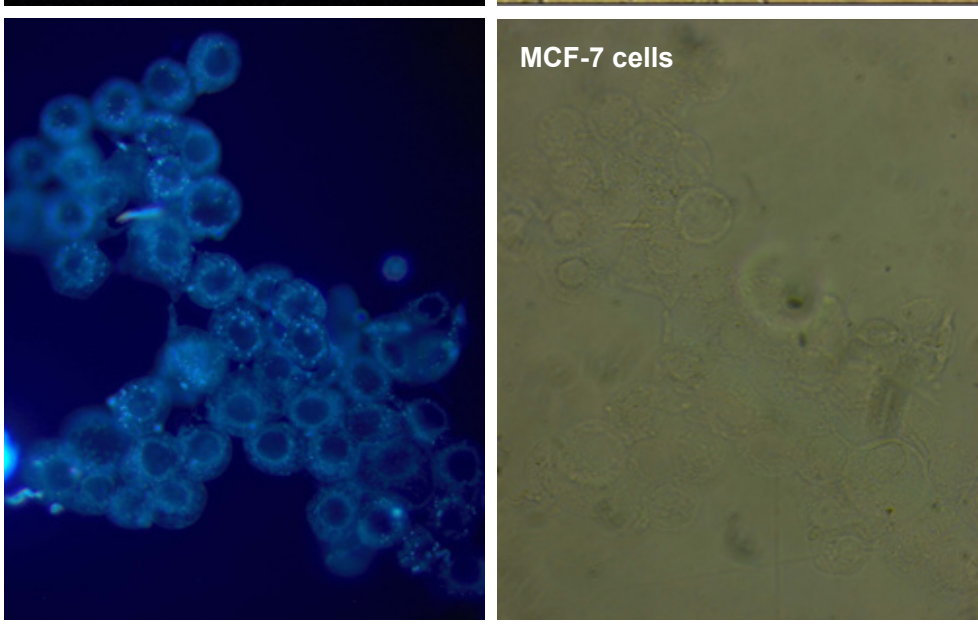

Figure 4 (A) Testing of affinity of I-methylpyrene-loaded nanoparticles (without anti-MUCI) and (B) C595 anti-MUCI I-methylpyrene-loaded nanoparticles toward MCF-7 cells. 


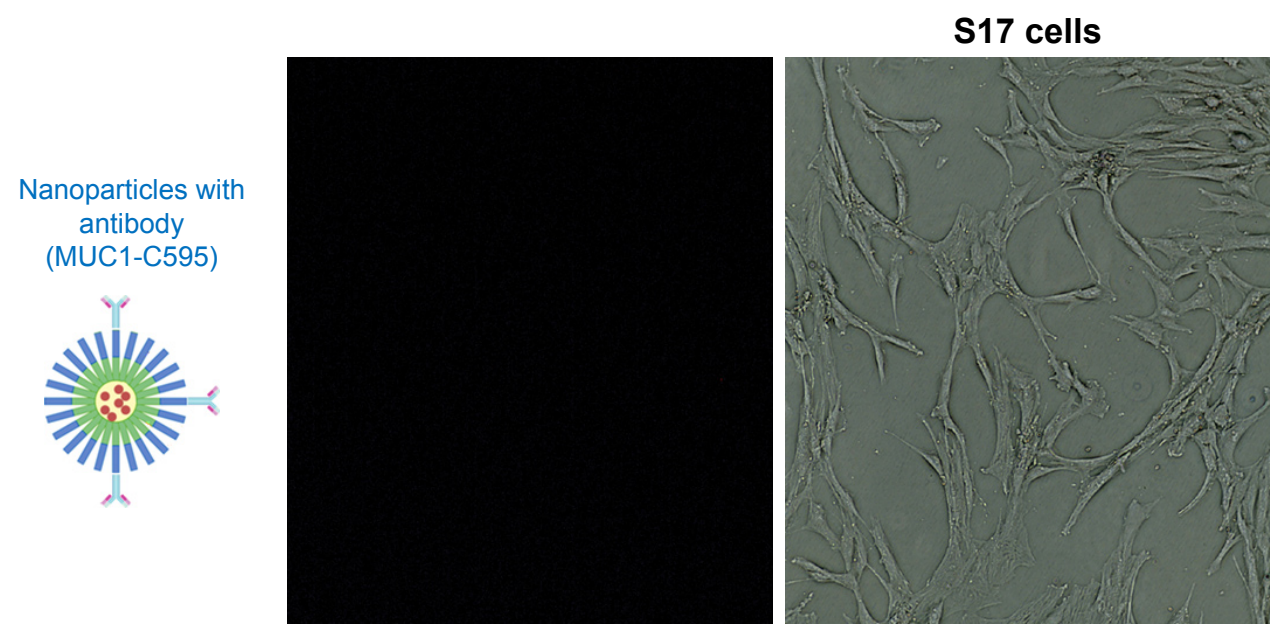

Figure 5 Testing of affinity of C595 anti-MUCI I-methylpyrene-loaded nanoparticles toward SI7 cells (control experiment).

\section{Detection of polymeric micelle-based bioassay for $\mathrm{MUCl}$ using ferrocene}

$\mathrm{CV}$ is a powerful analytical method that can reveal vital information about the oxidation/reduction processes of an element in a compound as well as its stability under certain conditions. CV can also be used to establish the diffusion coefficient of an analyte, the electron transfer kinetics, the electron stoichiometry of a system, and the precise reduction potential of any compound, which can be used as identification means. To perform CV, typically a potentiostat and a three-electrode cell are utilized to first apply a linear potential scan from potential $\mathrm{E}_{1}$ to potential $\mathrm{E}_{2}$, followed by a reverse scan back to potential $\mathrm{E}_{1}$. Since the $\mathrm{Fe}^{\mathrm{IIII}}$ redox couple of ferrocene $\left(\eta 5-\mathrm{C}_{5} \mathrm{H}_{5}\right)_{2} \mathrm{Fe}$ is a good illustration of a well-behaving electrochemically reversible system that easily undergoes one electron oxidation to form ferricenium $\left(\eta 5-\mathrm{C}_{5} \mathrm{H}_{5}\right)_{2} \mathrm{Fe}^{+}$cation, this is frequently used as a reference to determine standard reduction potentials of redox-active species. Additionally, since in a Nernstian system the current is directly proportional to concentration, the concentration of ferrocene can be determined by engendering a calibration curve of current vs concentration. Due to these features, ferrocene is indirectly
Fluorescence

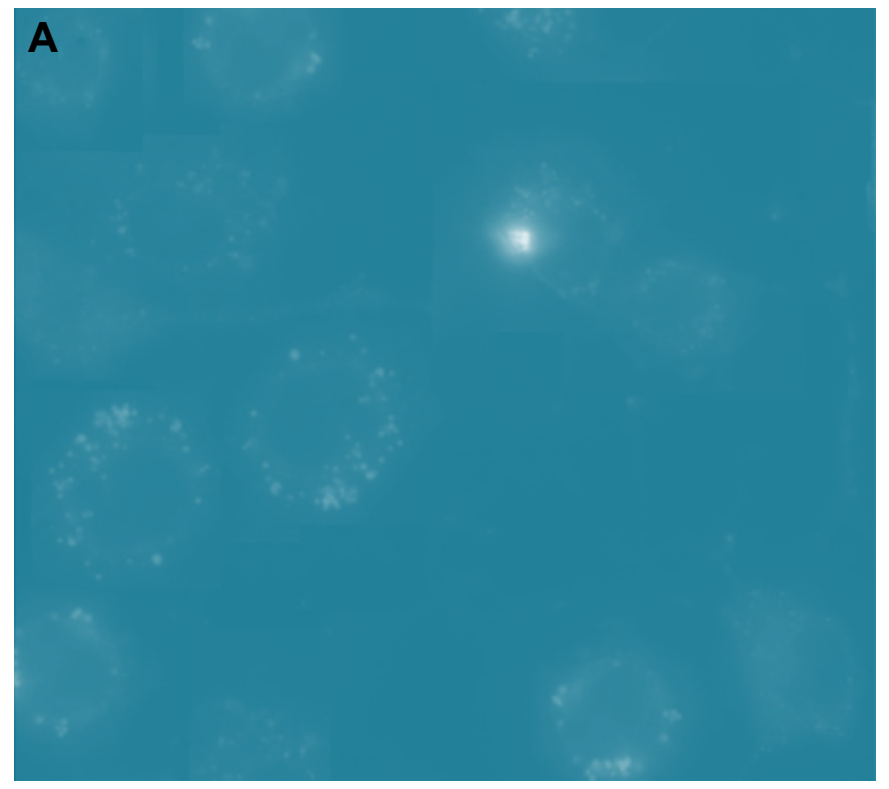

\section{Bright field}
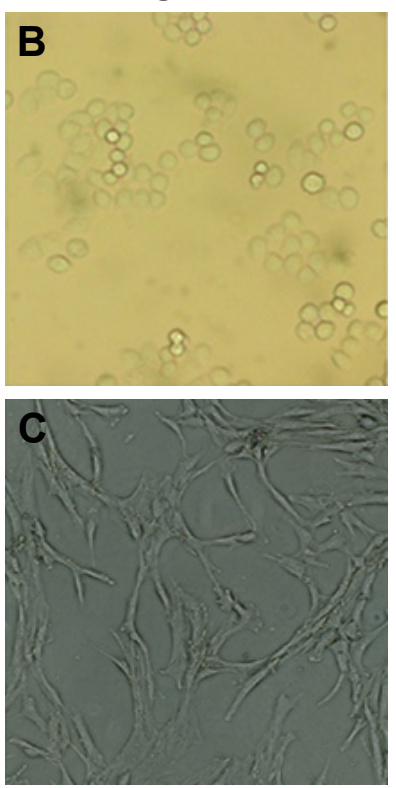

Figure 6 Testing of affinity of anti-MUCI I-methylpyrene-loaded nanoparticles toward MDA-MB-468 breast cancer cells. (B) MDA-MB-468 and (C) SI7 cells were seeded at a ratio of I:5 and incubated for I h with anti-MUCI-bioconjugated micelles. (A) After incubation and cell fixation, the increased uptake of anti-MUCI micelles by the human MUCI-expressing MDA-MB-468 cells was evident. 
used as an electrochemical indicator to report the presence of cancer marker (MUC1) within the cell lysate.

In this investigation, two different antibodies were used against MUC1, C595 and SM3, which, respectively, recognize the peptide epitope ARG-PRO-ALA-PRO and the epitope within the VNTR tandem repeat peptide, which is exposed only in underglycosylated MUC1 protein. ${ }^{32}$

In our assay, we used magnetic beads conjugated to SM3 antibody to capture the MUC1 at different concentrations of MCF-7 cell lysis solution $(1,000,100,10$, and 1 cell $/ \mathrm{mL})$. Collecting the magnetic beads from the cell lysis solution via an external magnet was followed by washing off nonspecifically bound biomolecules using PBS buffer. Then, the C595-labeled and loaded micelles were incubated with the sandwich magnetic beads (beadsSM3-MUC1) for $1 \mathrm{~h}$, followed by washing off unbound bioconjugated micelles, and a sandwich of micelle-biomarker-magnetic beads was obtained. After decreasing the $\mathrm{pH}$ of the sandwich solution, anodic $\left(E_{\mathrm{pa}}\right)$ and cathodic $\left(E_{\mathrm{pc}}\right)$ peak potentials of ferrocene $\left(\mathrm{Fe}\left(\mathrm{C}_{2} \mathrm{H}_{5}\right)_{2}{ }^{+} / \mathrm{Fe}\left(\mathrm{C}_{5} \mathrm{H}_{5}\right)\right)$ were obtained, indicating the presence of ferrocene molecules that were released from the micelle-biomarker-magnetic beads sandwich (Figure 7).

In this test, the intensity of the signal depends on the amount of ferrocene released into the medium. Since our micelles can encapsulate a large amount of ferrocene, this new bioassay enables us to detect the presence of the MUC1 biomarker within 10 cells/mL (Figure 8A) in less than $1 \mathrm{~min}$. As a result, the strong signal of $\mathrm{Fe}^{\mathrm{III} / \mathrm{II}}$ redox couple clearly illustrates the sensitivity and selectivity of this new bioassay toward low-abundance cancer biomarker candidate via signal amplification. The precision and the reproducibility of our assay were confirmed by measuring the relative standard deviation or coefficient of variation. Based on current intensity collected from repeating our new assay with four times of the sample containing 10 cells $/ \mathrm{mL}$, it was determined that the coefficient of variation was no more than $0.23 \%$ (Table 1 ).

A couple of control experiments were executed to ensure no false positives or signal interferences were obtained: 1) Nearly no electrochemical signals were observed when sandwich magnetic beads (beads-SM3-MUC1) were incubated with plain loaded polymeric micelles (no antibody
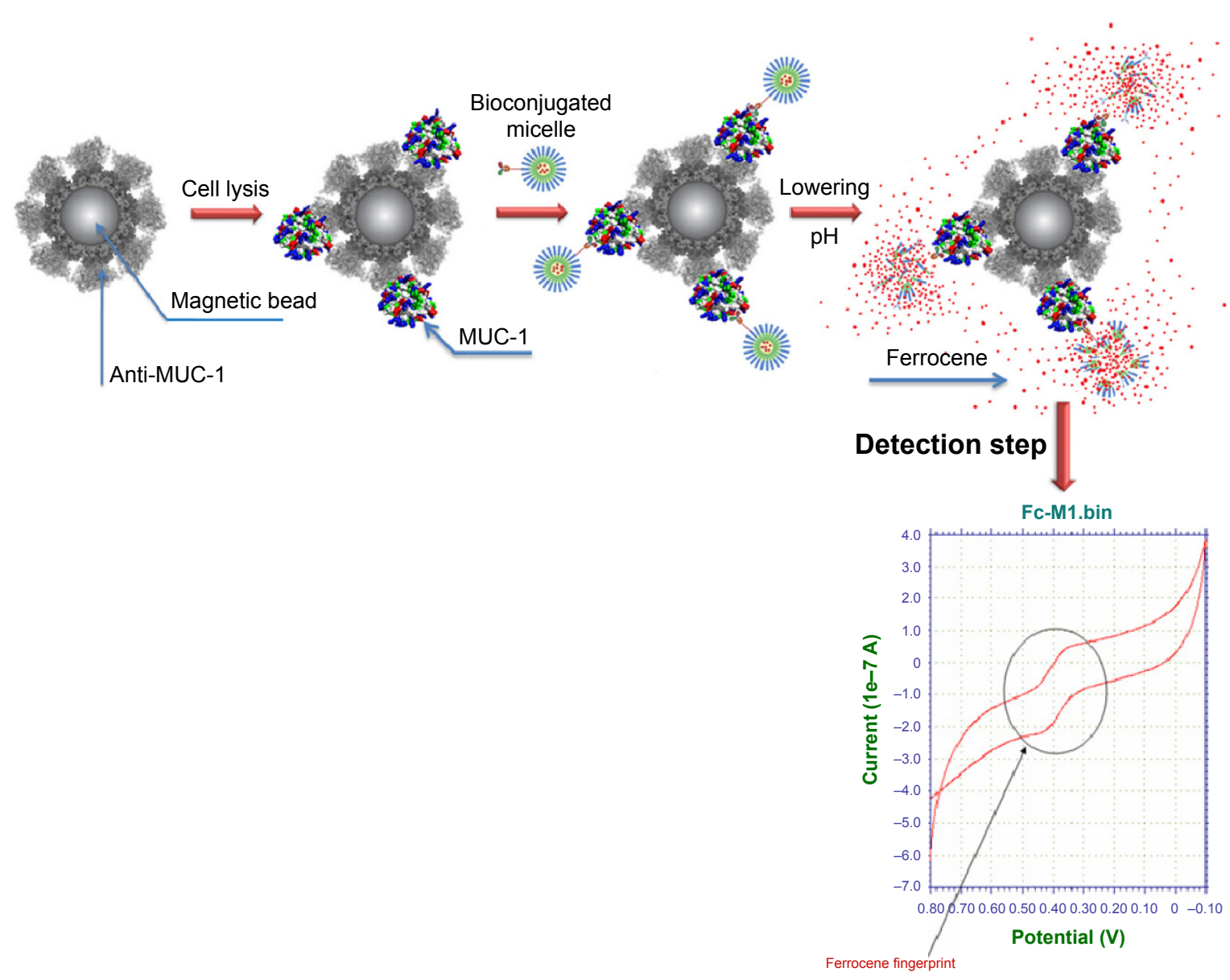

Figure 7 Schematic of the detection process of the new bioassay. 


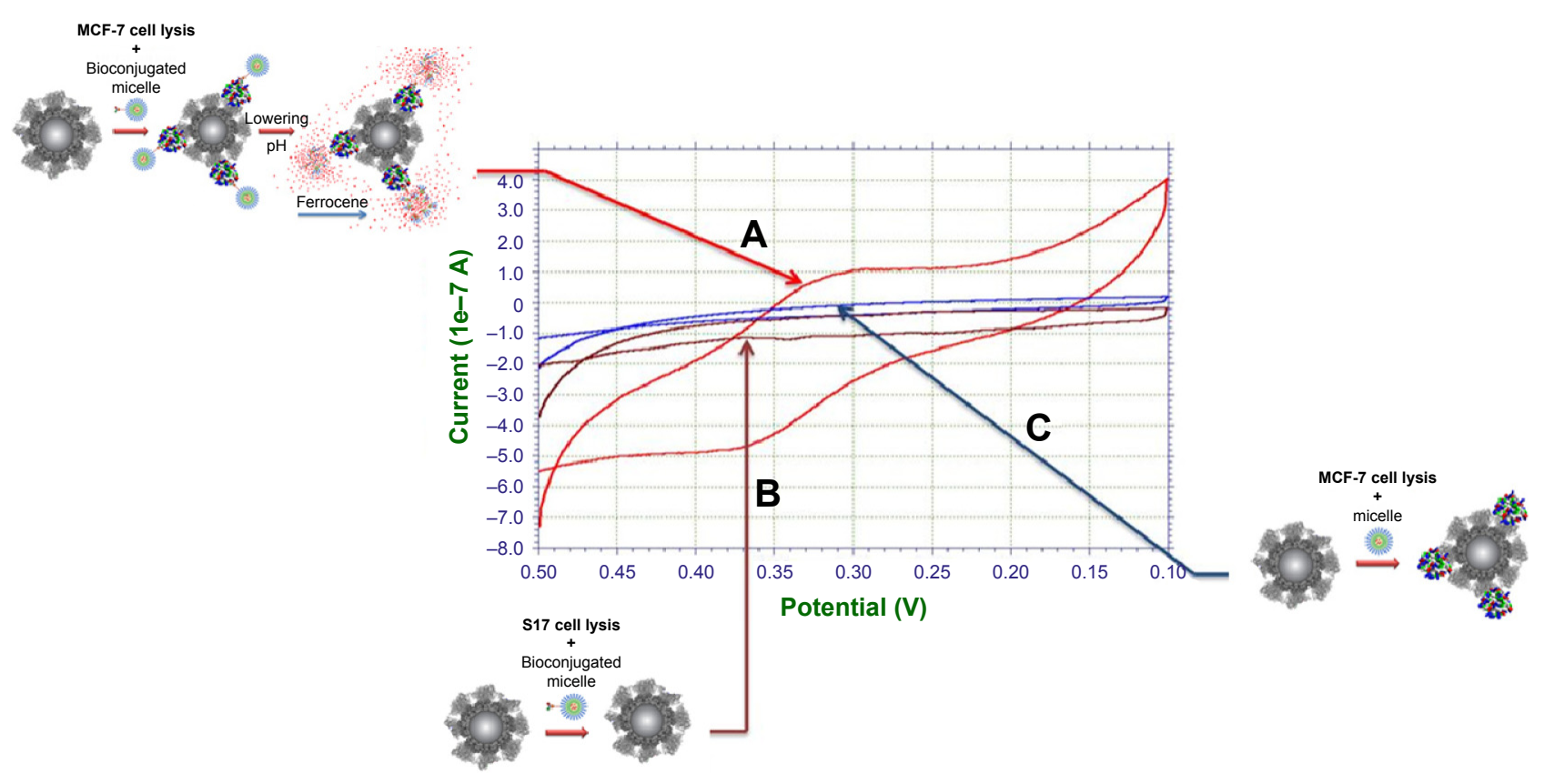

Figure 8 Ferrocene cyclic voltammetry readings of the event of binding between loaded polymeric micelle and MUCI biomarker. A: Detection of breast cancer biomarker MUCI using MCF-7 breast cancer cells and ferrocene-loaded micelles. B: Control experiment I: Detection of breast cancer biomarker MUCI using SI7 cell line instead of MCF-7 breast cancer cells. C: Control experiment 2: The detection step is performed using plain loaded polymeric micelles (no antibody is present on the surface).

on the surface), indicating the absence of nonspecific interactions between the plain micelles and the magnetic beads sandwich (Figure 8C). 2) Since S17 (mouse bone marrow stroma) cells have no MUC, MDA-MB-468 cell lysis solution was replaced with $\mathrm{S} 17$ cell lysis solution $(1,000$ cells $/ \mathrm{mL})$ and then incubated with C595-labeled and ferrocene-loaded polymeric micelles. This was followed by washing off unbound bioconjugated micelles, and again, no electrochemical signal for the ferrocene molecules was recorded (Figure 8B). Together, these observations clearly indicate the high selectivity of this new bioassay toward MUC1 biomarker.

\section{Conclusion}

Since $\mathrm{pH}$-sensitive polymeric nanoparticles have proven to be efficient and stable carriers (great stability and leakage proof), we encapsulated ferrocene molecules. The encapsulated ferrocene molecules were used as tracers to probe the event of binding of the antibody with its antigen. Using this new concept, we were able to detect our target, the MUC1, within 10 cells/mL in less than $1 \mathrm{~min}$, by first releasing the encapsulated ferrocene molecules into the solution via decreasing the $\mathrm{pH}$ and then measuring the electrochemical signal (current intensity)

Table I Relative standard deviation data of the new bioassay

\begin{tabular}{ll}
\hline Mean, ampere & $1.09 \times 10^{-7}$ \\
Standard deviation, ampere & $0.0024 \times 10^{-7}$ \\
Coefficient of variation & $0.23 \%$ \\
\hline
\end{tabular}

using CV. Consequently, we developed an extremely selective and sensitive bioassay with signal amplification capability. This new bioassay has numerous advantages over the existing techniques: 1) The amplification process allows the detection of low-abundance biomarkers, where every single event of binding between the antibody and antigen is indicated by hundreds of thousands of ferrocene molecules that are released into the solution. 2) These new polymeric nanoparticles have great stability and leakage proof. 3) This newly developed bioassay will open the door to new cheap, robust, and disposable electrochemical biosensors for cancer biomarker detection, with smaller sample volume requirements.

\section{Acknowledgment}

This work was supported by the Kuwait Foundation for Advancement of Sciences under the project number P11514SC-02. The authors also thank the Research Sector (RSPU) facility, for allowing the use of their NMR, GC-MS, and Fluromax 4 (GS 01/03 and GS 03/01).

\section{Disclosure}

The authors report no conflicts of interest in this work.

\section{References}

1. Boylan B, Rice AS, Dunn AL, et al. Characterization of the anti-factor VIII immunoglobulin profile in patients with hemophilia A by use of a fluorescence-based immunoassay. J Thromb Haemost. 2015; 13(1):47-53. 
2. Kraj M, Kruk B, Lech-Marańda E, Warzocha K, Prochorec-Sobieszek M. High incidence of intact or fragmented immunoglobulin in urine of patients with multiple myeloma. Leuk Lymphoma. 2015;56(12):3348-3356

3. Zhou F, Wang M, Yuan L, Cheng Z, Wu Z, Chen H. Sensitive sandwich ELISA based on a gold nanoparticle layer for cancer detection. Analyst. 2012;137(8):1779-1784.

4. Carlsson GH, Nicholls P, Svistunenko D, Berglund GI, Hajdu J. Complexes of horseradish peroxidase with formate, acetate, and carbon monoxide. Biochemistry. 2005;44(2):635-642.

5. Jou AF-J, Lu C-H, Ou Y-C, et al. Diagnosing the miR-141 prostate cancer biomarker using nucleic acid-functionalized CdSe/ZnS QDs and telomerase. Chem Sci. 2015;6(1):659-665.

6. Behnke T, Mathejczyk JE, Brehm R, et al. Target-specific nanoparticles containing a broad band emissive NIR dye for the sensitive detection and characterization of tumor development. Biomaterials. 2013; 34(1):160-170.

7. Jeschke S, Lusuardi L, Myatt A, Hruby S, Pirich C, Janetschek G. Visualisation of the lymph node pathway in real time by laparoscopic radioisotope and fluorescence-guided sentinel lymph node dissection in prostate cancer staging. Urology. 2012;80(5):1080-1086.

8. Mehta PK, Kalra M, Khuller GK, Behera D, Verma I. Development of an ultrasensitive polymerase chain reaction-amplified immunoassay based on mycobacterial RD antigens: implications for the serodiagnosis of tuberculosis. Diagn Microbiol Infect Dis. 2012;72(2):166-174.

9. Rajkovic A, El Moualij B, Uyttendaele M, et al. Immunoquantitative real-time PCR for detection and quantification of Staphylococcus aureus enterotoxin B in foods. Appl Environ Microbiol. 2006 72(10):6593-6599.

10. Chatterjee DK, Sitaraman K, Baptista C, Hartley J, Hill TM, Munroe DJ. Protein microarray on-demand: a novel protein microarray system. PLoS One. 2008;3(9):e3265.

11. Forster RJ, Bertoncello P, Keyes TE. Electrogenerated chemiluminescence. Annu Rev Anal Chem (Palo Alto Calif). 2009;2:359-385.

12. Liu N, Ma Z. Au-ionic liquid functionalized reduced graphene oxide immunosensing platform for simultaneous electrochemical detection of multiple analytes. Biosens Bioelectron. 2014;51:184-190.

13. Gehring AG, Crawford CG, Mazenko RS, van Houten LJ, Brewster JD. Enzyme-linked immunomagnetic electrochemical detection of Salmonella typhimurium. J Immunol Methods. 1996;195(1-2):15-25.

14. Kazuhisa Kubotsu, Masaaki Kida, Sachiko Goto, inventors; Wako Pure Chemical Industries, Ltd. (Osaka), assignee. Immunoassay using liposomes. United States patent US 5654156 A. 1997 Aug 5.

15. Sułkowski WW, Pentak D, Nowak K, Sułkowska A. The influence of temperature, cholesterol content and $\mathrm{pH}$ on liposome stability. $\mathrm{J} \mathrm{Mol}$ Struct. 2005;744-747:737-747.
16. Thongborisute J, Tsuruta A, Kawabata Y, Takeuchi H. The effect of particle structure of chitosan-coated liposomes and type of chitosan on oral delivery of calcitonin. J Drug Target. 2006;14(3):147-154.

17. Bégu S, Aubert Pouëssel A, Lerner DA, Tourné-Péteilh C, Devoisselle JM. Liposil, a promising composite material for drug storage and release. J Control Release. 2007;118(1):1-6.

18. Ruysschaert T, Germain M, Gomes JF, et al. Liposome-based nanocapsules. IEEE Trans Nanobioscience. 2004;3(1):49-55.

19. Akbarzadeh A, Rezaei-Sadabady R, Davaran S, et al. Liposome: classification, preparation, and applications. Nanoscale Res Lett. 2013; $8(1): 102$.

20. Vermette P, Meagher L, Gagnon E, Griesser HJ, Doillon CJ. Immobilized liposome layers for drug delivery applications: inhibition of angiogenesis. J Control Release. 2002;80(1-3):179-195.

21. Kufe DW. Mucins in cancer: function, prognosis and therapy. Nat Rev Cancer. 2009;9(12):874-885.

22. Cheng AK, Su H, Wang YA, Yu HZ. Aptamer-based detection of epithelial tumor marker mucin 1 with quantum dot-based fluorescence readout. Anal Chem. 2009;81(15):6130-6139.

23. Danysh BP, Constantinou PE, Lukianova-Hleb EY, Lapotko DO, Carson DD. The MUC1 ectodomain: a novel and efficient target for gold nanoparticle clustering and vapor nanobubble generation. Theranostics. 2012;2(8):777-787.

24. Yu C, Hu Y, Duan J, et al. Novel aptamer-nanoparticle bioconjugates enhances delivery of anticancer drug to MUC1-positive cancer cells in vitro. PLoS One. 2011;9(6):e24077.

25. Gendler SJ. MUC1, the renaissance molecule. J Mammary Gland Biol Neoplasia. 2001;6(3):339-353.

26. Carson DD. The cytoplasmic tail of MUC1: a very busy place. Sci Signal. 2008;1(7):pe35.

27. Mouffouk F, da Costa AM, Martins J, Zourob M, Abu-Salah KM, Alrokayan SA. Development of a highly sensitive bacteria detection assay using fluorescent $\mathrm{pH}$-responsive polymeric micelles. Biosens Bioelectron. 2011;26(8):3517-3523.

28. Mouffouk F, Chishti Y, Jin Q. Polymeric micelle-based bioassay with femtomolar sensitivity. Anal Biochem. 2008;372(2):140-147.

29. Moatsou D, Li J, Ranji A, et al. Self-assembly of temperatureresponsive protein-polymer bioconjugates. Bioconjug Chem. 2015; 26(9):1890-1899.

30. Ling D, Park W, Park SJ, et al. Multifunctional tumor pH-sensitive selfassembled nanoparticles for bimodal imaging and treatment of resistant heterogeneous tumors. J Am Chem Soc. 2014;136(15):5647-5655.

31. Hamley IW. Nanoshells and nanotubes from block copolymers. Soft Matter. 2005;1(1):36-43.

32. Singh R, Bandyopadhyay D. MUC1: a target molecule for cancer therapy. Cancer Biol Ther. 2007;6(4):481-486.
International Journal of Nanomedicine

\section{Publish your work in this journal}

The International Journal of Nanomedicine is an international, peerreviewed journal focusing on the application of nanotechnology in diagnostics, therapeutics, and drug delivery systems throughout the biomedical field. This journal is indexed on PubMed Central, MedLine, CAS, SciSearch $®$, Current Contents $\AA /$ Clinical Medicine,

\section{Dovepress}

Journal Citation Reports/Science Edition, EMBase, Scopus and the Elsevier Bibliographic databases. The manuscript management system is completely online and includes a very quick and fair peer-review system, which is all easy to use. Visit http://www.dovepress.com/ testimonials.php to read real quotes from published authors. 